\title{
The Effects of Administrated Dexamethasone on Neurologic Assessment in Neuro-oncology Scale in Patients with Intracranial Tumors
}

Muhamad Ibnu Sina ${ }^{1^{*}}$, Cut Aria Arina, Irina Kemala Nasution

${ }^{1}$ Department of Neurology, Universitas Sumatera Utara, H. Adam Malik General Hospital, Medan, Indonesia

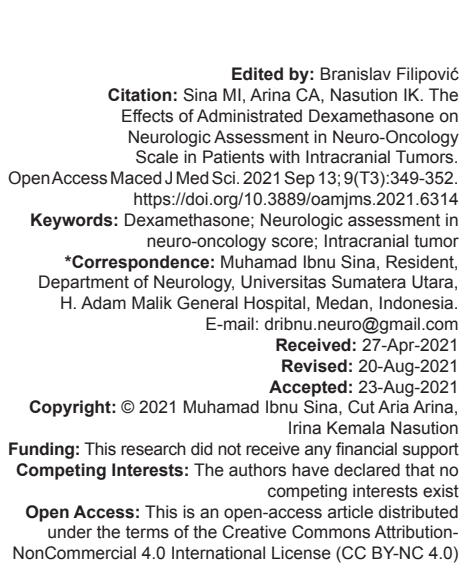

\begin{abstract}
BACKGROUND: In intracranial tumors, glucocorticoids are the main therapy to treat peritumoral edema. Neurologic Assessment in Neuro-Oncology (NANO) score is an instrument that can assess neurological function objectively and practically in patients with intracranial tumors.

AIM: This study aims to determine the effect of dexamethasone administration on the NANO score of intracrania tumor patients.

METHODS: This study was a pre-experimental study with a pre and post-test design at the $\mathrm{H}$. Adam Malik Genera Hospital in Medan from March to September 2020. The study population was intracranial tumor patients. The research subject were 37 subjects taken consecutively. Treated with dexamethasone injection, then examined the NANO score before and after receiving dexamethasone injection on days 1, 2, and 3. Statistical analysis with Friedman test.

RESULTS: Based on the demographic characteristics of the research subjects, the mean age was $53.29 \pm 8.5$ years Most of the research subjects were male $(54.1 \%)$ while female $(45.9 \%)$. Most types of intracranial tumors were secondary tumors $(59.5 \%)$ while primary tumors $(40.5 \%)$. The significant effect of dexamethasone on NANO score in patients with intracranial tumors $(p<0.001)$
\end{abstract}

CONCLUSION: There is an effect of dexamethasone on the NANO score of patients with intracranial tumors

\section{Background}

Intracranial tumors are abnormal masses of tissue in the cranium, cells grow and divide uncontrollably by mechanisms that control normal cells. Intracranial tumors or brain tumors are classified into primary brain tumors and metastatic brain tumors [1]

Brain tumors have continued to increase in incidence during the last decade in several countries [2]. The epidemiology of brain tumors covers about $85-90 \%$ of all central nervous system tumors. The mortality rate is $4.25 / 100,000$ population/year where the mortality is higher in men [3]. One of the main causes of morbidity and mortality in brain tumor patients is the development of uncontrolled cerebral edema and causing cerebral herniation [4].

Patients with brain tumors often present with neuroemergency due to increased intracranial pressure (ICP). This is mainly due to the spacepressing effect of peritumoral edema or diffuse edema, in addition to the large mass size or ventriculomegaly due to obstruction by the mass.

In patients with brain tumors, glucocorticoids are the mainstay of treatment for peritumoral edema [5]. In three-quarters of these patients, those receiving corticosteroid therapy experienced a general change in symptoms within $48 \mathrm{~h}$ [6].

The recommended agent is dexamethasone [3]. Dexamethasone is preferred because of its very low mineralocorticoid activity, long half-life, and high potency [7]. Dexamethasone treats edema in tumors by decreasing the expression of Vascular Endothelial Growth Factor (VEGF) thereby improving blood brain barrier dysfunction [8].

According to a study conducted by Palombi et al. [9] reported the results that there was a statistically significant difference in results associated with dexamethasone administration on the improvement of glioma symptoms. According to Kural et al. [10], conducting a study on the effect of giving dexamethasone $16 \mathrm{mg}$ for 2 days on edema volume reported the result that there was a decrease in edema volume by $1.7 \%$ compared to before dexamethasone administration.

Neurologic Assessment in Neuro-Oncology (NANO) score is an instrument that can assess neurological function objectively and practically in patients with intracranial tumors. Apart from being used to assess patient progressivity, NANO scores are also 
able to predict patient survival. This suggests that the NANO score can be an alternative in assessing clinical outcome [11].

This study aims to determine the effect of dexamethasone administration on the clinical outcome of intracranial tumors according to the NANO score.

\section{Method}

This research is a pre-experimental study with a pre and post-test design. The study was conducted at RSUP $H$. Adam Malik Medan from March to September 2020. The study population was intracranial tumor patients. Thirty-seven subjects in this research were taken consecutively. Subject was treated by administering dexamethasone injection to intracranial tumor patients were undergoing treatment in an integrated inpatient room. Then a clinical outcome examination is carried out using a NANO score before and after receiving dexamethasone injection on days 1, 2, and 3. Statistical analysis using the Windows SPSS (Statistical Product and Science Service) version 22.0 computer program used the Friedman test.

\section{Results and Discussion}

\section{subjects}

\section{Demographic characteristics of research}

Intracranial tumor patients who underwent treatment at RSUP Haji Adam Malik Medan in the period March to September 2020, there were 37 study subjects who met the inclusion and exclusion criteria so they were included in this study.

Based on the demographic characteristics of research subjects, it was found that age had a mean of $53.29 \pm 8.5$ years. Most of the research subjects were male, amounting to 20 subjects $(54.1 \%)$, while women were 17 subjects (45.9\%). Most types of intracranial tumors were secondary tumors totaling 22 subjects $(59.5 \%)$ while primary tumors totaled 15 subjects $(40.5 \%)$ Table 1 . The mean age of the subjects in this study is relevant to a previous study conducted by Mariska et al. [12]. which reported that the mean age of patients with intracranial tumors was $51.36 \pm 2.85$ years. This is also in line with the study of Rambe et al. [5] who found that the mean age of intracranial tumor patients was 51.45 (11-87) years. When compared with the results of the above studies, it can be seen that the majority of tumor cases occur in the age group $>40$ years, then this result is in accordance with the results of other studies where the age factor does influence the incidence of
Table 1: Demographic characteristics of research subjects

\begin{tabular}{|c|c|c|c|}
\hline Variable & Mean & $\mathrm{N}$ & $\%$ \\
\hline Age (mean \pm standard deviation) & $53.29 \pm 8.5$ & & \\
\hline \multicolumn{4}{|l|}{ Gender } \\
\hline Male & & 20 & 54.1 \\
\hline Female & & 17 & 45.9 \\
\hline \multicolumn{4}{|l|}{ Types of tumors } \\
\hline Primary & & 15 & 40.5 \\
\hline Secondary & & 22 & 59.5 \\
\hline
\end{tabular}

intracranial tumor disease [12]. Intracranial tumors can occur at any age, but the incidence of intracranial tumors increases with age, especially in late middle age [5], [12].

The sex characteristics of the subjects of this study are relevant to previous studies conducted by the research of Rambe et al. [5] and Mariska et al. [12] which showed that there were more brain tumor sufferers in men than women. According to Mckinney [13] reported that men are more often diagnosed with intracranial tumors than women, with a ratio of 1.5: 1. Intracranial tumors can occur in both men and women, however, both primary and metastatic intracranial tumors are more common in men than in women [12], [13].

In this study, it was found that the most characteristic types of intracranial tumors were metastatic tumors, namely 25 patients $(67.6 \%)$. This is in accordance with the results of the study by Mariska et al. [13] which found that 16 patients (53.3\%) had metastatic brain tumors. However, it is different from the results of the study by Rambe et al. [5], which found that 56 subjects $(74.7 \%)$ had primary brain tumors and 19 (25.3\%) secondary brain tumors. Brain metastases are the most common intracranial tumors. The incidence of brain metastases over time increases with the sophistication of detection of malignancies and the development of cancer management. Metastatic brain tumors occupy the most frequent intracranial tumors, surpassing primary tumors [14].

The Effect of Dexamethasone Administration on the NANO Score of Intracranial Tumor Patients Based on the data normality test, it shows that the NANO scores of the research subjects before giving dexamethasone, giving dexamethasone on days 1,2 , and 3 are not normally distributed so it requires a non-parametric analysis test, namely, the Friedman test. Based on the Friedman test, it was found that there was a significant effect of dexamethasone on the NANO score of patients with intracranial tumors $(p<0.001)$. Then proceed with post hoc analysis using the Wilcoxon test and it was found that there was a significant difference in the mean NANO score between before giving dexametasone with the $1^{\text {st }}, 2^{\text {nd }}$ and $3^{\text {rd }}$ day administration, $1^{\text {st }}$ day to $2^{\text {nd }}$ and $3^{\text {rd }}$ day, while the NANO score on day 2 and 3 , there was no significant difference in mean Table 2. The results of this study are relevant to previous studies conducted by Palombi et al. [9] reporting that there were statistically significant differences in results associated with dexamethasone administration on the improvement of glioma symptoms. 
Table 2: The effects of administrated dexamethasone on neurologic assessment in neuro-oncology scale in patients with intracranial tumors

\begin{tabular}{lll}
\hline NANO score & Median (minimum-maximum) & $\mathrm{P}$ \\
\hline Before dexamethasone administration & $7(2-18)$ & 0.000 \\
Day 1 Injection & $6(2-16)$ & \\
Day 2 Injection & $5(2-16)$ & \\
Day 3 Injection & $5(2-15)$ & \\
\hline${ }^{*}$ Friedman test. Wilcoxon post hoc values: before vs. day $1 \mathrm{P}=0.01$; before vs. day, $2 \mathrm{P}<0.001$; before vs. \\
day $3 \mathrm{P}<0.001$; day 1 vs. day $2 \mathrm{P}=0.002$; day 1 vs. day $3 \mathrm{P}=0.002$; day 2 vs. day $3 \mathrm{P}=0.632$.
\end{tabular}

According to Kural et al. [10], conducting a study on the effect of giving dexamethasone $16 \mathrm{mg}$ for 2 days on edema volume reported the result that there was a decrease in edema volume by $1.7 \%$ compared to before dexamethasone administration.

Corticosteroids have been widely used in tumor therapy and are useful in brain tumor patients with significant peritumoral edema accompanied by a neurological deficit [15]. Three-quarters of patients receiving corticosteroid therapy experience a general change in symptoms within $48 \mathrm{~h}$ [6]. Corticosteoid administrationis veryeffective in reducing cerebraledema and improving symptoms caused by cerebral edema, the effects of which can be seen within 24-72 $\mathrm{h}$. The recommended agent is dexamethasone with an intravenous bolus dose of $10 \mathrm{mg}$ followed by a maintenance dose of 16-20 mg/day intravenously then tappering off 2-16 $\mathrm{mg}$ (in divided doses) depending on the clinic.

According to Nayak et al. [16] reported the use of the NANO score as a clinical outcome parameter for patients with intracranial tumors who had an inter observer agreement value $>90 \%$ and kappa values ranging from 0.35 to 0.83 . According to research conducted by Ung et al. [17] reported that the initial NANO score had a correlation with the survival of glioma patients at 3.6, and 12 months $(p>0.001)$. The NANO score is a specific scale in oncology cases and can be used to assess glioma patients. According to Lee et al. [18], the NANO score is a more detailed and objective scale in assessing neurological function and can also be used to predict the prognosis of glioma patients. Lee et al. [18] divided the cut-off Nano score 0-7 and 8-23 and looked at survival and found that patients with a Nano score 0-7 had a higher survival rate than those with a score of $8-23$ (25.2 vs. 12.4 months; $p=0.023$ ).

\section{Conclusion}

Corticosteroids have been widely used in tumor therapy and are useful in brain tumor patients with significant peritumoral edema and neurological deficits. In this study, there was a significant effect of dexametasone on the NANO score of patients with intracranial tumors.

\section{References}

1. American Association of Neurological Surgerons (AANS). Brain Tumors. Available from: https://www.aans.org/2012. [Last accessed on 2021 May 14].

2. Satria A. Two-year Life Expectancy for Patients with Low Grade and High Grade Glioma Receiving Radiation Therapy. Scientific Papers. Semarang: Diponegoro University; 2011.

3. National Cancer Management Committee (KPKN). Brain Tumor. Jakarta: Ministry of Health of the Republic of Indonesia. National Cancer Management Committee; 2017.

4. Fan Z, Sehm T, Rauh M, Buchfelder M, Eyupoglu IY, Savaskan NE. Dexamethasone alleviates tumor-associated brain damage and angiogenesis. PLoS One. 2014;9(4):e93264. http://doi.org/10.1371/journal.pone.0093264

PMid:24714627

5. Kaal EA, Vecht CJ. The management of brain edema in brain tumors. Curr Opin Oncol 2004;16(6):593-600. http://doi. org/10.1097/01.cco.0000142076.52721.b3

PMid:15627023

6. Drappatz J, Schiff D, Kesari S, Norden AD, Wen PY. Medical management of brain tumor patients. Neurol Clin. 2007;25(4):1035-71. http://doi.org/10.1016/j.ncl.2007.07.015 PMid: 17964025

7. Husna U, Dalhar M. Pathophysiology and management of cerebral edema. MNJ. 2017;3(2):94-107.

8. Setiawan A, Pudjonarko D, Tasworo D. The effect of dexamethasone administration on plasma $D$ Dimer levels in brain tumor patients. Med Hosp. 2015;3(1):25-31.

9. Palombi L, Marchetti $P$, Salvati M, Osti MF, Frati L, Frati A. Interventions to reduce neurological symptoms in patients with GBM receiving radiotherapy: From theory to clinical practice. Anticancer Res 2018;38:2423-7. http://doi.org/10.21873/ anticanres.12494

PMid:29599372

10. Kural C, Atac GK, Tehli O, Solmaz I, Temiz C, Hodaj I, Izci Y. The evaluation of the effects of steroid treatment on the tumor and peritumoral edema by DWI and MR spectroscopy in brain tumors. Neurol Neurochir Pol. 2018;52(4):495-504. http://doi. org/10.1016/j.pjnns.2018.03.002 PMid:29588064

11. Neuro-Oncology Study Group. Neurooncology Textbook. $1^{\text {st }}$ ed. Jakarta: Association of Indonesian Neuroscientists (PERDOSSI); 2019. p. 1-209.

12. Mariska, Nasution IK, Fithrie A. Association between ages and glucocorticoid-induced diabetes mellitus incidence in intracranial tumor patients. Int J Res Sci Manag 2020;7(7):17-22.

13. Mckinney PA. Brain tumours: Incidence, survival, and aetiology J Neurol Neurosurg Psychiatry. 2004;75(2):12-7. http://doi. org/10.1136/jnnp.2004.040741 PMid:15146034

14. Chitra I, Andriani R. Secondary brain tumors (Metastases). In: Aninditha T, Andriani R, Malueka RG, editors. Neurooncology Textbook. Jakarta: Neuro-Oncology Study Group, Indonesian Association of Neuroscientists Indonesian Medical Publishers; 2019. p. 199-213.

15. Schultz H, Rasmussen BK, Kristensen PL, Jensen AK, Bjergaard UP. Early incidence of glucocorticoid-induce diabetes in patients with brain tumors: A retrospective study of the first day of treatment. Neurooncol Pract. 2017;5(3):170-5. http://doi.org/10.1093/nop/npx027 PMid:31385948

16. Nayak L, DeAngelis LM, Brandes AA, Peereboom DM, Galanis E, Lin NU, et al. The neurologic assessment in neuro 
oncology (NANO) scale: A tool to assess neurologic function for integration into the response assessment in neuro oncology (RANO) criteria. Neuro Oncol. 2017;19(5):625-35. http://doi. org/10.1093/neuonc/nox029

PMid:28453751

17. Ung TH, Ney DE, Damek D, Rusthoven CG, Youssef AS, Lillehei KO, et al. The neurologic assessment in neuro oncology (NANO) scale as an assessment tool for survival in patients with primary glioblastoma. Neurosurgery 2018;84(3):687-95. http:// doi.org/10.1093/neuros/nyy098

PMid:29618103

18. Lee J, Park SH, Kim YZ. Prognostic evaluation of neurological assessment of the neuro oncology scale in glioblastoma patients. Brain Tumour Res Treatment. 2018;6(1):22-30. http:// doi.org/10.14791/btrt.2018.6.e1

PMid:29644808 